nephron

Experimental

Nephrology

and Genetics
Nephron 2019;142:117-124

DOI: $10.1159 / 000497162$
Received: August 8, 2018

Accepted after revision: January 1, 2019

Published online: February 6, 2019

\title{
Renal Consequences of Therapeutic Interventions in Premature Neonates
}

\author{
Hayley J. Fryer Gavin I. Welsh \\ Bristol Renal, Bristol Medical School, University of Bristol, Bristol, UK
}

\section{Keywords}

Preterm birth - Kidney disease - Tocolytics - Corticosteroids . Antibiotics $\cdot$ Angiotensin-converting enzyme

\begin{abstract}
An infant is described as "preterm" if they are born before 37 weeks of gestation. As nephrogenesis does not complete until 36 weeks of gestation, premature infants are often born with underdeveloped kidneys. Current evidence strongly suggests that this leaves those born prematurely more susceptible to developing kidney-related conditions later in life. Although the incidence of premature birth steadily increases each year in the United Kingdom, reports of perinatal death following preterm labour are falling. This is mainly attributed to the development of antenatal drugs, such as tocolytics, corticosteroids and antibiotics. Though these drugs have effectively reduced the incidence of premature-birth-related deaths, evidence suggests that they may be nephrotoxic. This review will describe the experimental evidence that some therapeutics are disadvantageous to kidney functions later on in life.

(c) 2019 S. Karger AG, Basel
\end{abstract}

\section{Introduction}

An infant is described as "preterm" if they are born before 37 weeks of gestation. Although the number of infants born prematurely rises yearly in the United Kingdom, the incidence of premature-birth-related deaths is decreasing. This is mainly attributed to the development of antenatal drugs. Although there is a decreased risk of death, those born prematurely are more likely to have underdeveloped kidneys than infants born at term, as nephrogenesis does not complete until week 36 of gestation. Consequently, premature infants are often born with a reduced nephron count and low glomerular filtration rate (GFR) [1].

Studies have highlighted the potential nephrotoxic effects of various drugs, which premature infants are exposed to both in utero and postnatally. Such drugs include tocolytics, corticosteroids, antibiotics, non-steroidal anti-inflammatory drugs (NSAIDs), and angiotensin-converting enzyme (ACE) inhibitors. As these drugs are administered before the kidneys are fully developed, it is essential to understand their poten-

\section{KARGER}

(c) 2019 S. Karger AG, Basel

E-Mail karger@karger.com

www.karger.com/nef
Dr. Gavin I. Welsh

Bristol Renal, Bristol Medical School, University of Bristol

Dorothy Hodgkin Building, Whitson St

Bristol BS1 3NY (UK)

E-Mail g.i.welsh@ bristol.ac.uk 


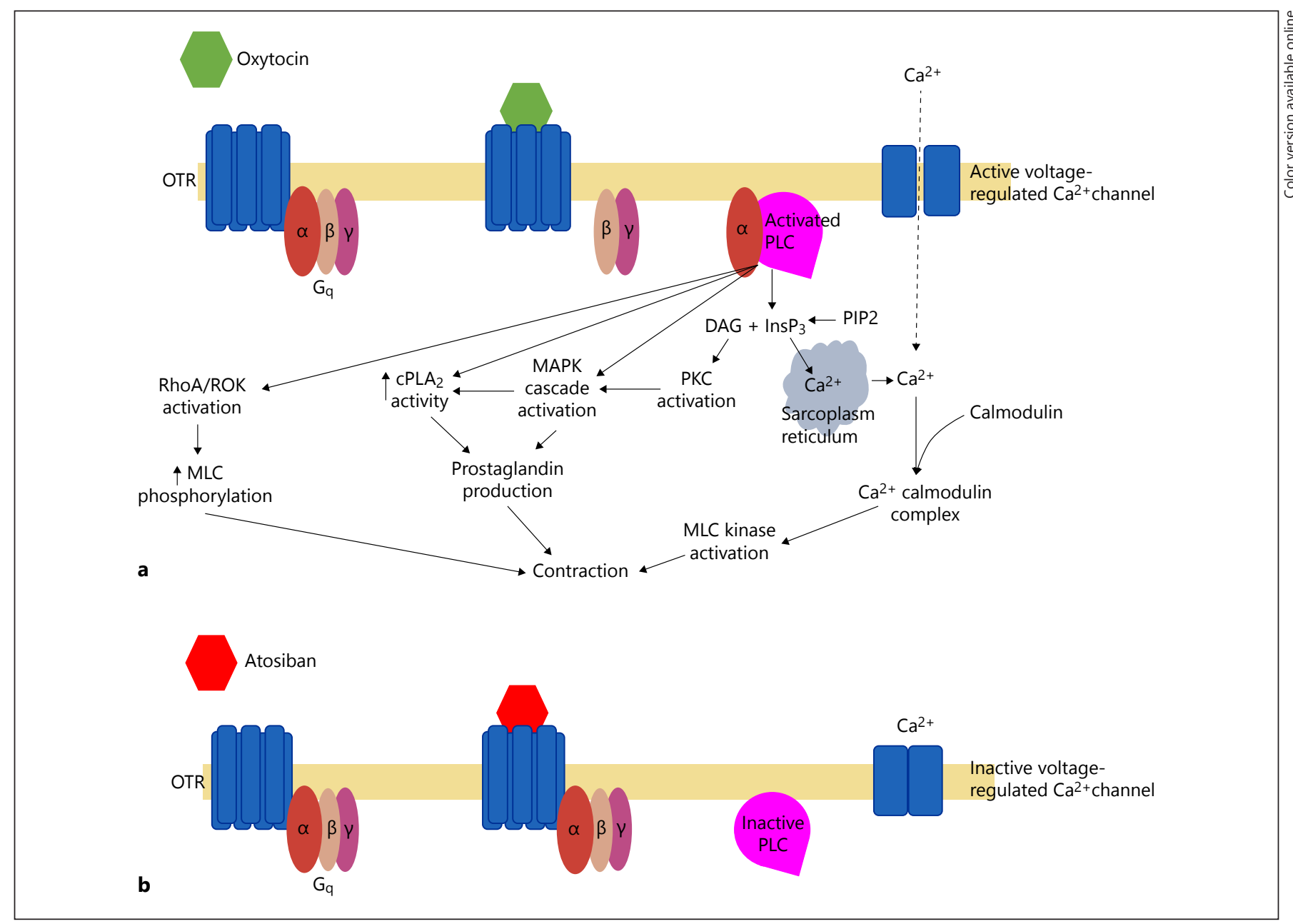

Fig. 1. a Schematic diagram of oxytocin-induced myometrial contraction. Adapted from [3]. OTR, oxytocin receptor; InsP3, inositol-trisphosphate; PLC, phospholipase C; PIP2, phosphatidylinositol bisphosphate; DAG, diacylglycerol; PKC, protein kinase C;

tial renal implications on the developing neonate. This review provides a detailed summary of the research describing the effects of these drugs on kidney health.

\section{Tocolytics}

Spontaneous preterm labour accounts for one third of preterm births, and is the main cause of neonatal illness and death [2]. Tocolytics are a group of medications used to delay premature labour. This allows for treatment with organ-maturing drugs, such as corticosteroids, to maximise chance of survival.

A tocolytic commonly used in the United Kingdom is Atosiban, an oxytocin receptor (OTR) antagonist. Oxyto-
MAPK, mitogen-activated protein kinase; cPLA2, cytosolic phospholipase A2; MLC, myosin light chains. b Schematic diagram of Atosiban-induced inhibition of the Gq pathway, leading to myometrial relaxation.

cin is a peptide hormone that initiates uterine contractions by binding to its OTR on myometrial cells. OTRs belong to the G-protein-coupled receptor family and act through a $\mathrm{G}_{\mathrm{q}}$ pathway to initiate myometrial contraction (Fig. 1a). If left uninhibited, these contractions will lead to labour [3]. Atosiban is a peptide analogue of oxytocin and is therefore able to bind to the OTR with high affinity. However, unlike oxytocin, it does not initiate the $\mathrm{G}_{\mathrm{q}}$ pathway, thus inhibiting myometrial contraction and delaying labour (Fig. 1b) [4].

Numerous studies have highlighted potential nephrotoxic outcomes following Atosiban treatment. Reversi et al. [3] found that treatment with Atosiban prevented cell growth of human embryonic kidney cells in a concentration-dependent manner. It is suggested that 


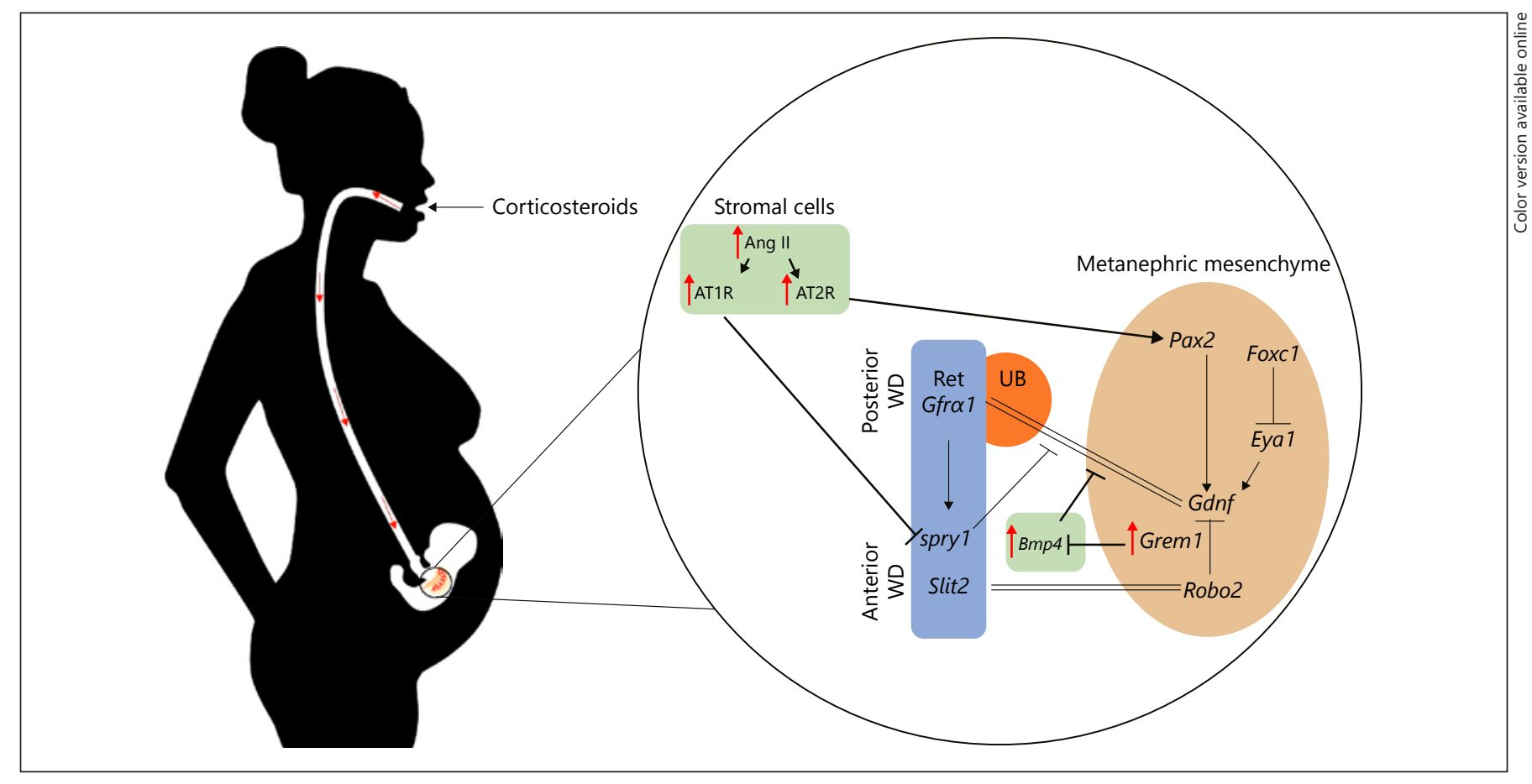

Fig. 2. Schematic diagram illustrating alterations to foetal renal gene expression following maternal corticosteroid treatment. = binding, $\rightarrow$ activates, $\dashv$ inhibits. UB, ureteric bud; WD, wolffian duct; Gdnf, glial cell-line derived neurotrophic factor; Ang II, angiotensin II.

Atosiban may activate the $G_{i}$ pathway, which has been linked to the inhibition of cell proliferation. This could lead to a reduction in renal cell numbers and have negative consequences in the developing kidneys of the neonate.

Oxytocin is important for kidney development and function [5]. As Atosiban does not specifically target myometrial cells, it is possible that it may interfere with other processes. Amaral et al. [6] found that treatment with Atosiban reduced oxytocin-induced renal vasodilation, which is important for sodium excretion in the urine. A reduction in oxytocin-induced renal vasodilation increases renal sodium, which can cause hypertension and other kidney-related diseases [6]. Sodium retention may be particularly detrimental to preterm neonates, who already have poor sodium excretion mechanisms.

Treatment with Atosiban has been shown to have a depressive effect on carbonic anhydrase (CA) [7]. CA is an enzyme which has a key role in facilitating acid-base regulation within the kidneys. By inhibiting CA, Atosiban may have a negative effect on the kidneys' ability to maintain homeostasis. Poor acid-base regulation in the kidneys can cause a build-up of acid in the body, leading to conditions such as metabolic acidosis, which is associated with kidney damage, uremic bone disease and mortality [8].

Another tocolytic commonly used in the United Kingdom is Nifedipine. This is a calcium channel antagonist, which inhibits myometrial contraction by limiting the concentration of calcium within uterine cells [9]. Currently, there is a lack of research exploring the effect of Nifedipine on foetal kidney development; however, when administered intravenously into adults, Nifedipine was shown to increase GFR [10]. As preterm infants typically have low a GFR, Nifedipine could prove advantageous and improve kidney function soon after birth. However, more research is required to determine the effect of administering this drug to underdeveloped kidneys.

\section{Antenatal Corticosteroids}

Antenatal corticosteroids, such as Betamethasone and Dexamethasone, are routinely given to women in the United Kingdom during preterm labour. They accelerate the maturation of foetal lungs, and reduce the incidence 
of respiratory distress syndrome, which can prove fatal [11].

Research in rodents, sheep and non-human primates indicates that antenatal corticosteroids may be harmful to neonatal kidneys by significantly reducing nephron number [12]. Dickinson et al. [13] found that external administration of corticosteroids significantly increased the expression of genes such as BMP4 and TGF- $\beta_{1}$ [13]. BMP4, a bone morphogenetic protein, is expressed in the stromal cells surrounding the wolffian duct. In a normal system, BMP4 inhibits Glial cell-line derived neurotrophic factor from binding to the ureteric bud (UB), thus inhibiting ectopic branching [14]. However, when upregulated, BMP4 is believed to cause the early cessation of nephron branching, leading to reduced nephron numbers [13]. TGF- $\beta_{1}$ has been shown to inhibit branching morphogenesis in cell culture and is therefore believed to limit nephrogenesis when upregulated [15]. These authors also found that treatment with corticosteroids increased expression of Gremlin, an inhibitor of BMP4 [13]. They concluded that the probable cause of this increased expression was in response to the upregulation of $B M P 4$, to prevent a more severe nephron deficit from occurring (Fig. 2) [13].

Moritz et al. [16] found that treatment with Dexamethasone significantly increases the expression of angiotensin-II (Ang-II), and its receptors AT1R and AT2R. During nephrogenesis, Ang-II promotes UB outgrowth by inhibiting negative regulators such as spry1 [17]. When upregulated, Ang-II, AT1R and AT2R appear to cause the premature maturation of the foetal kidney, thereby limiting nephrogenesis and leading to a decreased GFR and lower urinary output (Fig. 2) [16].

Research exploring the implications of in utero exposure to corticosteroids in human models is lacking. A study by van den Anker et al. [18] reported prenatal exposure to betamethasone had significant effects on the renal function of preterm infants in the first few days of life. However, this study had a small sample size of 6 participants and its findings may therefore not be generalisable to the wider population. Consequently, further research exploring the implications of in utero exposure to corticosteroids is required.

\section{Antibiotics}

Antibiotics are frequently used to treat bacterial infections. Preterm infants are significantly more likely to contract an infection post-birth than those born at term and therefore postnatal treatment with antibiotics is probable
[19]. Additionally, antibiotics can cross the placenta, meaning neonates are also often exposed to them in utero. Although treatment with antibiotics has been shown to effectively treat infections, there has been long-standing concern over their impact on the developing kidneys.

\section{Aminoglycosides}

Aminoglycosides, such as gentamicin, are used to treat gram-negative bacterial infections. In utero exposure to these drugs can impair nephrogenesis, leading to a reduction in nephron number and alterations to glomerular size and shape [20]. As aminoglycoside antibiotics are not readily metabolised, they are filtered by the glomeruli and absorbed by proximal tubule cells via endocytosis [21]. Once absorbed, they can cause necrosis to the tubules of the nephron and inhibit the reabsorption of key nutrients (Fig. 3) [22]. The effect of postnatal exposure to aminoglycosides is not well researched. Some studies demonstrate that treatment with these antibiotics has no nephrotoxic effects, while others suggest that aminoglycosides increase the risk of kidney damage and renal failure [20, 23]. Further research is therefore required to assess the true renal effect of postnatal exposure to these antibiotics.

\section{Glycopeptides}

Glycopeptide antibiotics, such as vancomycin, are used to treat infections caused by Gram-positive bacteria. Kidney damage after treatment with these drugs is rare and is thought to occur primarily in those with predisposing factors such as older age or who already have reduced renal function [24]. In such patients, it is hypothesised that these antibiotics cause oxidative stress and damage to the glomeruli and proximal tubules, which reduces kidney function [25]. Research suggests that exposure to glycopeptides is not nephrotoxic when used in premature infants and in utero exposure does not appear to influence renal development in the neonate [26, 27]. However, as research exploring the renal effects of these antibiotics is lacking, further exploration of the topic is required to determine whether glycopeptide usage in premature infants is truly safe.

\section{Fluoroquinolones}

Fluoroquinolone antibiotics are used to treat a variety of common illnesses such as urinary tract infections. As with glycopeptide antibiotics, nephrotoxic outcomes following treatment with fluoroquinolones appear to be rare, with instances of reduced renal function only being reported in adults with predisposing factors [28]. Consequently, these antibiotics are generally regarded as safe to 


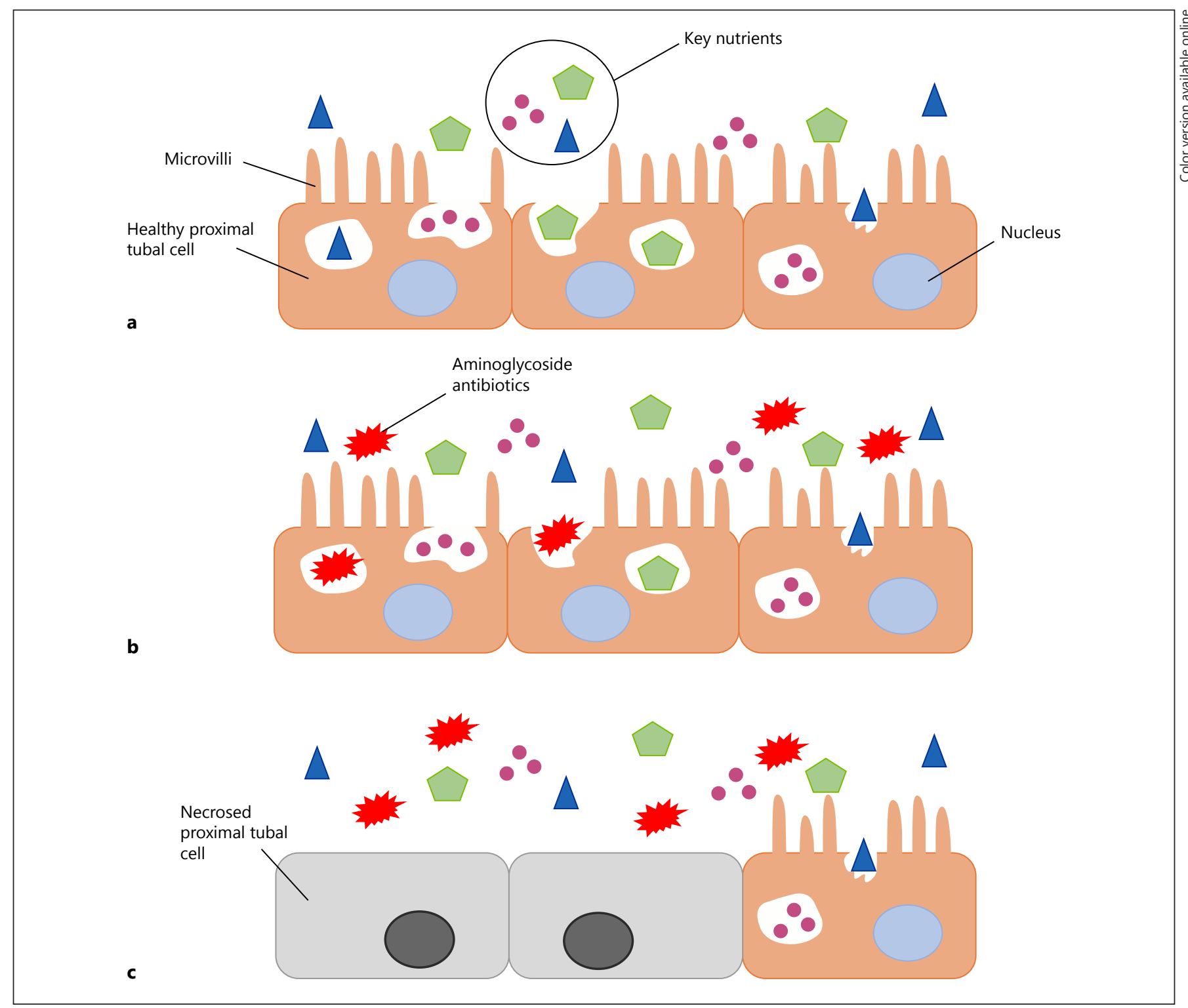

Fig. 3. Schematic diagram illustrating proximal tubal damage following aminoglycoside antibiotic treatment. a Healthy proximal cell absorbing key nutrients via endocytosis. b Proximal tubal cell absorbing aminoglycoside antibiotics via endocytosis. c Necrosed proximal cell unable to absorb key nutrients.

use in the new born. However, research exploring the renal implications of fluoroquinolone usage in the premature neonate is lacking and consequently requires further work.

\section{Cephalosporins}

Cephalosporins are broad-spectrum antibiotics, which are used to treat a variety of conditions. The incidence of renal impairment in adults following treatment with these drugs is low but poor tubular transportation in pre- mature neonates can cause concentrations of cephalosporins to increase to nephrotoxic levels [29]. Research has shown that postnatal exposure to cephalosporins is a risk factor for developing acute kidney injury and failure in premature infants [30].

\section{Penicillin}

Penicillin is a commonly used antibiotic which treats a variety of bacterial infections. Although renal toxicity following treatment with these drugs is uncommon, 
in utero exposure has been linked to a reduction in nephron number and inflammation to the renal cortex [31].

\section{Macrolides}

Macrolides, such as erythromycin, are bacteriostatic antibiotics, which act against gram-positive bacteria. Research suggests that these antibiotics may indirectly cause acute kidney injury by inhibiting cytochrome $\mathrm{P} 450$ isoenzyme, CYP 3 A4 [32]. This isoenzyme metabolises various drugs, which are administered clinically [33]. Inhibition of CYP 3A4 could therefore cause any drugs used in conjunction with macrolides, such as corticosteroids or other antibiotics, to concentrate to nephrotoxic levels.

\section{Tetracyclines}

Tetracycline antibiotics are commonly used to treat skin infections such as acne. Nephrotoxic outcomes following treatment with these drugs are rare, and consequently randomised trials exploring their impact on kidney function are lacking. However, case studies have reported incidence of acute nephritis and reduced GFR following tetracycline treatment [34]. Research exploring the molecular mechanism for tetracycline transport in the kidneys suggests that the impairment of organic anion transporters in the proximal tubules following exposure to these antibiotics may cause incidences of nephrotoxicity [35]. Many of the case reports were of individuals who had pre-existing renal impairment. As premature infants often have reduced kidney function shortly after birth, they may be at risk of nephrotoxicity following treatment with tetracycline antibiotics.

\section{Sulphonamides}

Sulphonamide antibiotics are used to treat a variety of common ailments such as soft tissue and urinary tract infections. Sulfamethoxazole is a commonly used sulphonamide and is typically used in conjunction with trimethoprim, another antimicrobial agent. Data reporting the effects of these drugs in premature infants in lacking; however, research exploring the impact of sulfamethoxazole-trimethoprim usage in adults have reported increases in serum creatinine concentration and acute kidney injury $[36,37]$.

\section{Non-Steroidal Anti-Inflammatory Drugs}

NSAIDs are used in the treatment of patent ductus arteriosus (PDA). The ductus arteriosus is a blood vessel, which connects the aorta and pulmonary artery in utero.

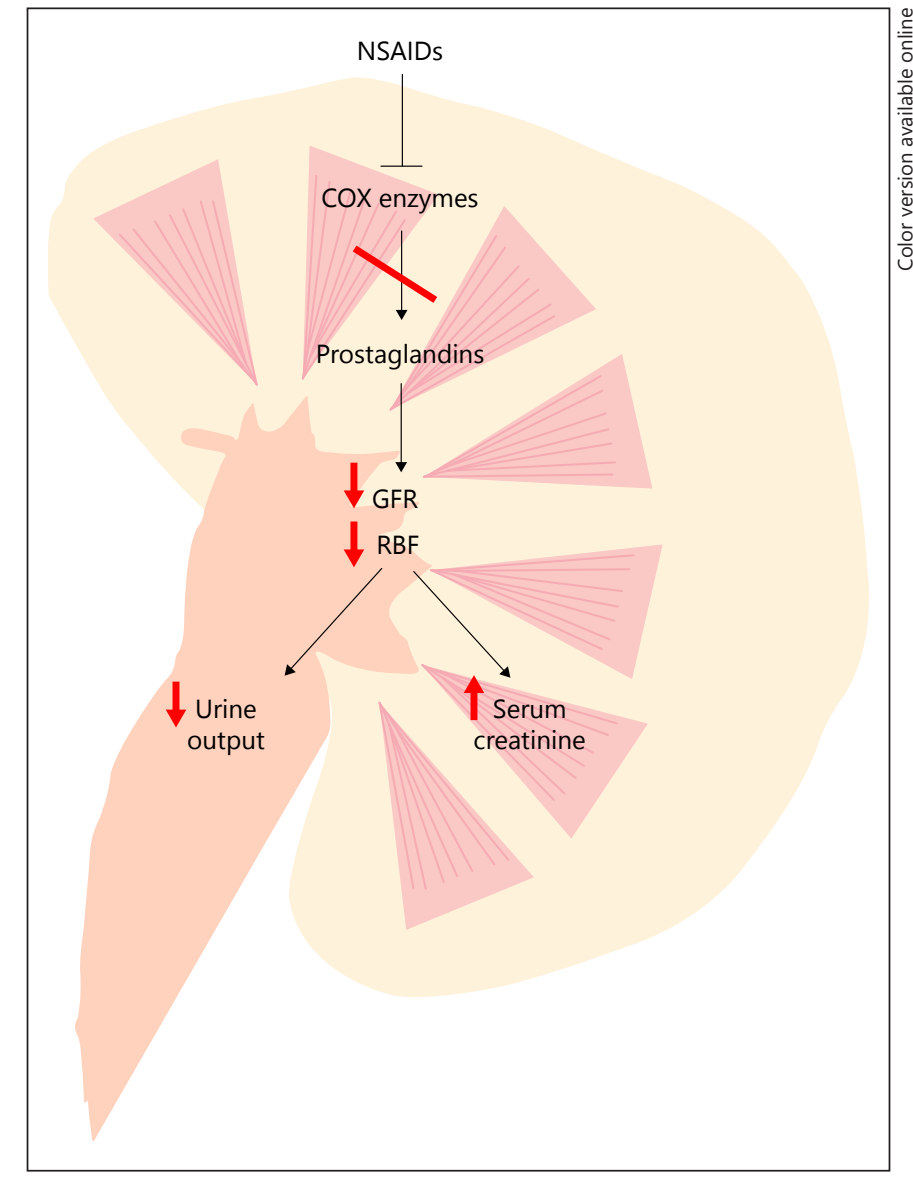

Fig. 4. The Effect of NSAIDs on renal function. NSAIDs inhibit COX enzymes from producing prostaglandins, which reduces GFR and RBF. This lowers urinary output and increases serum concentrations of creatinine. NSAIDs, non-steriodal anti-inflammatory drugs; COX, cyclooxygenase; GFR, glomerular filtration rate; RBF, renal blood flow.

Postnatally, this blood vessel is expected to close. If it does not, oxygenated and non-oxygenated blood can mix freely within the heart, which can result in infant morbidity. PDA is more commonly observed in preterm infants, due to their developmental immaturity [38]. Indomethacin and Ibuprofen are currently used in the treatment of PDA.

NSAIDs function by inhibiting the production of prostaglandins, which are known to keep the ductus arteriosus open. This inhibition is not restricted to the heart, and consequently prostaglandin concentrations are reduced throughout the body. In the kidney, prostaglandins have important roles in maintaining renal blood flow and GFR [39]. Consequently, treatment with Indomethacin and Ibuprofen has been shown to lower renal blood flow and GFR, leading to reduced urine production and increased concentrations of serum creatinine (Fig. 4) [40, 
41]. Increased serum creatinine can prove deleterious to health, and in some instances, treatment with NSAIDs has even been reported to cause renal failure in neonates [42].

A recent Cochrane review assessed the usage of paracetamol in the treatment of PDA. Results suggest that paracetamol is as effective as Indomethacin and Ibuprofen in treating this condition, with possibly fewer adverse side effects [43]. Currently, paracetamol is not recommended by NICE in the treatment of PDA, presumably as long-term data is not available for its usage. As a result, further research into the long-term implications of using paracetamol to treat $\mathrm{PDA}$ is required, to determine whether it truly is a suitable alternative to the current treatment options.

\section{ACE Inhibitors}

ACE inhibitors are used to treat instances of heart disease, such as hypertension [44]. ACE turns Ang I to Ang II, which results in vasoconstriction and promotes the release of aldosterone, a corticosteroid hormone that stimulates sodium absorption within the kidneys [45]. ACE inhibitors consequently cause blood vessel relaxation and induce sodium excretion by the kidneys, resulting in reduced blood pressure. It is well reported that those born prematurely frequently have increased blood pressure due to fewer functional glomeruli at birth [46]. Consequently, ACE inhibitors are often used in the postnatal care of premature neonates. Although these drugs successfully treat hypertension, there is concern over their potential nephrotoxic effects in premature infants.

Lindle et al. [47] conducted a retrospective review of 243 neonates with cardiac disease; 38 of these neonates were born prematurely. They found that treatment with the ACE inhibitors enalapril and captopril significantly lowered creatinine clearance and caused renal failure in $55 \%$ of premature neonates [47]. These findings are supported by case reports examining premature infants with heart disease treated with these drugs [48]. Normal renal function was achieved upon cessation of ACE inhibitor usage.

In utero exposure to ACE inhibitors, especially during the first trimester, has been linked to an increased risk of kidney malformation in the offspring [49]. As mentioned previously, Ang II acts via its receptors to regulate UB outgrowth, inhibiting negative regulators such as spry 1 [17]. Therefore, in utero exposure to ACE inhibitors could impede on nephrogenesis and lead to improper kidney structure at birth and these drugs are consequently not recommended for use during pregnancy.

\section{Conclusion}

As kidneys continue to develop up to 36 weeks of gestation, preterm infants are often born with reduced nephron numbers and consequently sub-optimal renal performance. The number of preterm neonates surviving infancy increases yearly in the United Kingdom. This is primarily due to the use of drugs such as tocolytics, corticosteroids, antibiotics, NSAIDs and ACE inhibitors. Consequently, there is a steadily growing population of individuals who were subjected to such drugs in utero and postnatally. Although these drugs have proven benefits in improving survivorship in preterm neonates, research has raised concerns over their potential deleterious effects on nephrogenesis and overall renal health. As preterm individuals are already born with fewer nephrons, any substance that further impinges on their nephritic health would be especially hazardous and may leave them at an increased risk of developing kidney-related illnesses later in life. This literature review has highlighted that research into the effects of pre- and postnatal exposure to many of these drugs is lacking in premature human models. Furthermore, the author could not find any literature exploring the long-term effects of these drugs on renal function. It is therefore essential for further research to be undertaken, to truly understand the implications of exposing premature infants to these drugs.

\section{Disclosure Statement}

The authors declare no conflicts of interest.

$\begin{array}{ll}\text { References } \quad 1 \text { Starr MC, Hingorani SR: Prematurity and fu- } \\ \text { ture kidney health: the growing risk of chron- } \\ \text { ic kidney disease. Curr Opin Pediatr 2018;30: } \\ & 228-235 . \\ 2 & \text { Tan TC, Devendra K, Tan LK, Tan HK: Toco- } \\ & \text { lytic treatment for the management of pre- } \\ & \text { term labour: a systematic review. Singapore } \\ & \text { Med J 2006;47:361-366. } \\ 3 \text { Reversi A, Rimoldi V, Marrocco T, Cassoni P, } \\ \text { Bussolati G, Parenti M, Chini B: The oxytocin } \\ \text { receptor antagonist atosiban inhibits cell } \\ \text { growth via a "biased agonist" mechanism. J } \\ \text { Biol Chem 2005;280:16311-16318. }\end{array}$


4 Akerlund M, Bossmar T, Brouard R, Kostrzewska A, Laudanski T, Lemancewicz A, Serradeil-Le Gal C, Steinwall M: Receptor binding of oxytocin and vasopressin antagonists and inhibitory effects on isolated myometrium from preterm and term pregnant women. $\mathrm{Br}$ J Obstet Gynaecol 1999;106:1047-1053.

5 Schmidt A, Jard S, Dreifuss JJ, Tribollet E: Oxytocin receptors in rat kidney during development. Am J Physiol 1990;259:F872-F881.

6 Amaral NO, de Oliveira TS, Naves LM, Filgueira FP, Ferreira-Neto ML, Schoorlemmer $\mathrm{GH}$, de Castro CH, Freiria-Oliveira AH, Xavier CH, Colugnati DB, Rosa DA, Blanch GT, Borges CL, Soares CM, Reis AA, Cravo SL, Pedrino GR: Efferent pathways in sodium overload-induced renal vasodilation in rats. PLoS One 2014;9:e109620.

7 Kocyigit UM, Taşkıran AŞ, Taslimi P, Yokuș A, Temel Y, Gulçin İ:Inhibitory effects of oxytocin and oxytocin receptor antagonist atosiban on the activities of carbonic anhydrase and acetylcholinesterase enzymes in the liver and kidney tissues of rats. J Biochem Mol Toxicol 2017;31

8 Kovesdy CP: Metabolic acidosis and kidney disease: does bicarbonate therapy slow the progression of CKD? Nephrol Dial Transplant 2012;27:3056-3062.

9 Flenady V, Wojcieszek AM, Papatsonis DN, Stock OM, Murray L, Jardine LA, Carbonne B: Calcium channel blockers for inhibiting preterm labour and birth. Cochrane Database Syst Rev 2014;6:CD002255.

10 Shoichi Y, Tsuneo K: Clinical effects of intravenous nifedipine on renal function. J Cardiovasc Pharmacol 1983;5:67-71.

11 Roberts D, Brown J, Medley N, Dalziel SR: Antenatal corticosteroids for accelerating fetal lung maturation for women at risk of preterm birth. Cochrane Database Syst Rev 2017; 3:CD004454.

12 Gubhaju L, Sutherland MR, Black MJ: Preterm birth and the kidney: implications for longterm renal health. Reprod Sci2011;18:322-333.

13 Dickinson H, Walker DW, Wintour EM, Moritz K: Maternal dexamethasone treatment at midgestation reduces nephron number and alters renal gene expression in the fetal spiny mouse. Am J Physiol Regul Integr Comp Physiol 2007;292:R453-R461.

14 Chen F: Genetic and developmental basis for urinary tract obstruction. Pediatr Nephrol 2009;24:1621-1632.

15 Sakurai H, Nigam SK: Transforming growth factor-beta selectively inhibits branching morphogenesis but not tubulogenesis. Am J Physiol 1997;272:F139-146.

16 Moritz KM, Johnson K, Douglas-Denton R, Wintour EM, Dodic M: Maternal glucocorticoid treatment programs alterations in the renin-angiotensin system of the ovine fetal kidney. Endocrinology 2002;143:4455-4463.

17 Yosypiv IV, Boh MK, Spera MA, El-Dahr SS: Downregulation of Spry-1, an inhibitor of GDNF/Ret, causes angiotensin II-induced ureteric bud branching. Kidney Int 2008;74: $1287-1293$
18 van den Anker JN, Hop WC, de Groot R, van der Heijden BJ, Broerse HM, Lindemans J, Sauer PJ: Effects of prenatal exposure to betamethasone and indomethacin on the glomerular filtration rate in the preterm infant. Pediatr Res 1994;36:578-581.

19 Seo K, McGregor JA, French JI: Preterm birth is associated with increased risk of maternal and neonatal infection. Obstet Gynecol 1992; 79:75-80.

20 Gilbert T, Lelievre-Pegorier M, Malienou R, Meulemans A, Merlet-Benichou C: Effects of prenatal and postnatal exposure to gentamicin on renal differentiation in the rat. Toxicology 1987;43:301-313.

21 Tune BM: Nephrotoxicity of beta-lactam antibiotics: mechanisms and strategies for prevention. Pediatr Nephrol 1997;11:768-772.

22 Martínez-Salgado C, López-Hernández FJ, López-Novoa JM: Glomerular nephrotoxicity of aminoglycosides. Toxicol Appl Pharmacol 2007;223:86-98.

23 Giapros VI, Andronikou S, Cholevas VI, Papadopoulou ZL: Renal function in premature infants during aminoglycoside therapy. Pediatr Nephrol 1995;9:163-166.

24 Elyasi S, Khalili H, Dashti-Khavidaki S, Mohammadpour A: Vancomycin-induced nephrotoxicity: mechanism, incidence, risk factors and special populations. A literature review. Eur J Clin Pharmacol 2012;68:1243-1255.

25 Nishino Y, Takemura S, Minamiyama Y, Hirohashi $\mathrm{K}$, Ogino $\mathrm{T}$, Inoue $\mathrm{M}$, Okada $\mathrm{S}$, Kinoshita H: Targeting superoxide dismutase to renal proximal tubule cells attenuates vancomycin-induced nephrotoxicity in rats. Free Radic Res 2003;37:373-379.

26 Reyes MP, Ostrea EM, Cabinian AE, Schmitt C, Rintelmann W: Vancomycin during pregnancy: does it cause hearing loss or nephrotoxicity in the infant? Am J Obstet Gynecol 1989;161:977-981.

27 Linder N, Edwards R, MeClead R, Mortensen ME, Walson P, Koren G: Safety of vancomycin with or without gentamicin in neonates. Neonatal Netw 1993;12:27-30.

28 Fanos V, Cuzzolin L: Fluoroquinolones in pediatrics and their nephrotoxicity in adults: minireview. J Chemother 2000;12:228-231.

29 Kaloyanides GJ: Antibiotic-related nephrotoxicity. Nephrol Dial Transplant 1994; 9(suppl 4):130-134.

30 Viswanathan S, Manyam B, Azhibekov T, Mhanna MJ: Risk factors associated with acute kidney injury in extremely low birth weight (ELBW) infants. Pediatr Nephrol 2012;27:303-311.

31 Nathanson S, Moreau E, Merlet-Benichou C, Gilbert T: In utero and in vitro exposure to beta-lactams impair kidney development in the rat. J Am Soc Nephrol 2000;11:874-884.

32 Watkins VS, Polk RE, Stotka JL: Drug interactions of macrolides: emphasis on dirithromycin. Ann Pharmacother 1997;31:349-356.

33 Ladda MA, Goralski KB: The effects of CKD on cytochrome P450-mediated drug metabolism. Adv Chronic Kidney Dis 2016;23:67-75.
34 Bihorac A, Ozener C, Akoglu E, Kullu S: Tetracycline-induced acute interstitial nephritis as a cause of acute renal failure. Nephron 1999;81:72-75.

35 Babu E, Takeda M, Narikawa S, Kobayashi Y, Yamamoto T, Cha SH, Sekine T, Sakthisekaran D, Endou H: Human organic anion transporters mediate the transport of tetracycline. Jpn J Pharmacol 2002;88:69-76.

36 Roy MT, First MR, Myre SA, Cacini W: Effect of co-trimoxazole and sulfamethoxazole on serum creatinine in normal subjects. Ther Drug Monit 1982;4:77-79.

37 Fraser TN, Avellaneda AA, Graviss EA, Musher DM: Acute kidney injury associated with trimethoprim/sulfamethoxazole. J Antimicrob Chemother 2012;67:1271-1277.

38 Dice JE, Bhatia J: Patent ductus arteriosus: an overview. J Pediatr Pharmacol Ther 2007;12: 138-146.

39 Dunn MJ, Scharschmidt L, Zambraski E: Mechanisms of the nephrotoxicity of non-steroidal anti-inflammatory drugs. Arch Toxicol Suppl 1984;7:328-337.

40 Van Overmeire B, Allegaert K, Casaer A, Debauche C, Decaluwé W, Jespers A, Weyler J, Harrewijn I, Langhendries JP: Prophylactic ibuprofen in premature infants: a multicentre, randomised, double-blind, placebo-controlled trial. Lancet 2004;364:1945-1949.

41 Cifuentes RF, Olley PM, Balfe JW, Radde IC, Soldin SJ: Indomethacin and renal function in premature infants with persistent patent ductus arteriosus. J Pediatr 1979;95:583-587.

42 Erdeve O, Sarici SU, Sari E, Gok F: Oral-ibuprofen-induced acute renal failure in a preterm infant. Pediatr Nephrol 2008;23:1565-1567.

43 Ohlsson A, Shah PS: Paracetamol (acetaminophen) for patent ductus arteriosus in preterm or low birth weight infants. Cochrane Database Syst Rev 2018;4:CD010061.

44 Wong J, Patel RA, Kowey PR: The clinical use of angiotensin-converting enzyme inhibitors. Prog Cardiovasc Dis 2004;47:116-130.

45 Ritter JM: Angiotensin converting enzyme inhibitors and angiotensin receptor blockers in hypertension. BMJ 2011;342:d1673.

46 Hughson M, Farris AB 3rd, Douglas-Denton R, Hoy WE, Bertram JF: Glomerular number and size in autopsy kidneys: the relationship to birth weight. Kidney Int 2003;63:21132122.

47 Lindle KA, Dinh K, Moffett BS, Kyle WB, Montgomery NM, Denfield SD, Knudson JD: Angiotensin-converting enzyme inhibitor nephrotoxicity in neonates with cardiac disease. Pediatr Cardiol 2014;35:499-506.

48 Lee GJ, Cohen R, Chang AC, Cleary JP: Angiotensin converting enzyme inhibitor (ACEI)-induced acute renal failure in premature newborns with congenital heart disease. J Pediatr Pharmacol Ther 2010;15:290-296.

49 Cooper WO, Hernandez-Diaz S, Arbogast PG, Dudley JA, Dyer S, Gideon PS, Hall K, Ray WA: Major congenital malformations after first-trimester exposure to ACE inhibitors. N Engl J Med 2006;354:2443-2451. 